\title{
Markers of ovarian antral follicular development in sheep: comparison of follicles destined to ovulate from the final or penultimate follicular wave of the estrous cycle
}

\author{
Srinivas V Seekallu, Behzad M Toosi, Anna T Grazul-Bilska ${ }^{1}$ and Norman C Rawlings \\ Department of Veterinary Biomedical Sciences, Western College of Veterinary Medicine, University of Saskatchewan, \\ Saskatoon, Saskatchewan, Canada S7N 5B4 and ${ }^{1}$ Department of Animal Sciences and Cell Biology Center, North \\ Dakota State University, Fargo, North Dakota 58105, USA \\ Correspondence should be addressed to N C Rawlings; Email: norman.rawlings@usask.ca
}

S V Seekallu is now at Manitoba Institute of Cell Biology, University of Manitoba, 675 McDermot Avenue, Winnipeg, Manitoba, Canada R3E 0V9

\begin{abstract}
Treatment of non-prolific western white-faced ewes with prostaglandin $\mathrm{F}_{2 \alpha}\left(\mathrm{PGF}_{2 \alpha}\right)$ and medroxyprogesterone acetate (MAP) increases the ovulation rate as a result of ovulations from the penultimate wave in addition to the final wave of the cycle. The objective of the current study was to evaluate the expression of markers of vascularization/angiogenesis, a marker of intercellular communication, and cellular proliferation and apoptosis in follicles from the penultimate and final waves. On day 8 of the estrous cycle, 15 ewes were administered a single injection of $\mathrm{PGF}_{2 \alpha}$ and an intravaginal MAP sponge, which remained in place for 6 days. Two days after sponge removal, ovaries which contained follicles from the penultimate and final waves were collected and processed for immunohistochemistry followed by image analysis, and for quantitative real-time RT-PCR. Expression of factor VIII (marker of vascularization), proliferating cell nuclear antigen, and GJA1 (CX43; marker of gap junctional communication) was greater $(P<0.05)$ in follicles from the final wave compared with follicles from the penultimate wave. For theca cells, mRNA expression for vascular endothelial growth factor (VEGF) was greater $(P<0.05)$ and tended to be greater $(P \leq 0.1$ and $\geq 0.05)$ for $G J A 1$ and endothelial nitric oxide synthase in follicles from the final wave compared with follicles from the penultimate wave. For granulosa cells, the mRNA expression for $G J A 1$ was greater $(P<0.05)$ and tended to be greater $(P \leq 0.1$ and $\geq 0.05)$ for $V E G F$ in follicles from the final wave compared with follicles from the penultimate wave. In conclusion, extension of the lifespan of follicles in the penultimate wave reduces follicular viability in the ewe.

Reproduction (2010) 140 559-568
\end{abstract}

\section{Introduction}

In cyclic ewes, ovarian antral follicles emerge and grow from a pool of small follicles ( 2 or $3 \mathrm{~mm}$ in diameter) in a wave-like pattern, reaching diameters of $\geq 5 \mathrm{~mm}$ before regression or ovulation (Schrick et al. 1993, Ginther et al. 1995, Bartlewski et al. 1999). In most cases, ovulatory follicles develop from the cohort of follicles from the last follicular wave of the estrous cycle (Bartlewski et al. 1999). However, ovulatory follicles can also be derived from the penultimate (second to last) wave of the cycle; these follicles may ovulate at the same time as follicles from the last follicular wave of the cycle (Bartlewski et al. 1999). The high ovulation rate in prolific Finn ewes is the result of ovulations from the penultimate wave in addition to the final wave of the cycle (Bartlewski et al. 1999). In a previous study (Bartlewski et al. 2003), treatment of non-prolific western white-faced (WWF) ewes with prostaglandin
$\mathrm{F}_{2 \alpha}\left(\mathrm{PGF}_{2 \alpha}\right)$ and medroxyprogesterone acetate (MAP) at midcycle changed follicular dynamics and increased ovulation rate by $\sim 50 \%$ due to ovulations from both the penultimate wave and the final wave of the cycle. However, $\mathrm{PGF}_{2 \alpha}$ and MAP treatment in non-prolific WWF ewes did not result in an increase in lambing rate (Davies 2005). The ovulatory follicle from the penultimate wave is older compared with the ovulatory follicle from the final wave of the cycle. However, the effect of the ovulation of aged follicles on fertility in sheep is not clear.

It has been demonstrated that follicular growth is influenced by numerous extra- and intrafollicular regulators such as angiogenic factors, estradiol $\left(E_{2}\right)$, insulin-like growth factors (IGFs), IGF-binding proteins, and others (Hunter et al. 2004). In fact, changes of vascularization and expression of some regulators, including angiogenic factors, are associated with follicular growth and/or atresia (Fraser 2006). 
Several angiogenic factors, including vascular endothelial growth factor (VEGF) and endothelial nitric oxide synthase (NOS3), are expressed in ovarian follicles of several species (Redmer \& Reynolds 1996, Grazul-Bilska et al. 2006).

Intercellular communication through gap junctions, which consist of proteins called gap junction proteins (also known as connexins, Cxs), is also required for normal ovarian folliculogenesis (Grazul-Bilska et al. 1997). GJA1 (Cx43) is the major gap junctional protein forming the channels within the granulosa cells and theca layers of the follicle (Kidder \& Mhawi 2002). Gap junction proteins play a significant role in the regulation of steroidogenesis, cell proliferation, and also cell survival. Changes in cell proliferation, apoptosis, and GJA1 production are associated with follicular growth and development or atresia (Jablonka-Shariff et al. 1994, Grazul-Bilska et al. 1997, Ackert et al. 2001, Kidder \& Mhawi 2002, Gershon et al. 2008).

We hypothesized that the lack of increased fertility in non-prolific WWF ewes with increased ovulation rates by $\mathrm{PGF}_{2 \alpha}$ and MAP sponge treatment could be partly explained by limited angiogenesis, limited cellular proliferation and gap junction expression, and increased apoptosis in preovulatory follicles with an extended lifespan from the penultimate wave of the cycle compared with the preovulatory follicles from the final wave of the cycle. Therefore, the objective of the present study was to evaluate 1) the expression of factor VIII, a marker of endothelial cells and thus vascularization; 2) the expression of markers of angiogenesis including VEGF and NOS3 mRNA; 3) the labeling index (LI), based on expression of proliferating cell nuclear antigen (PCNA), a marker of cellular proliferation; 4) apoptosis; and 5) the expression of GJA1, a marker of gap junctional communication, in preovulatory follicles obtained from the penultimate wave and the final wave of the estrous cycle in WWF ewes treated with $\mathrm{PGF}_{2 \alpha}$ and MAP.

\section{Results}

\section{Serum progesterone concentrations, follicular fluid $E_{2}$ concentrations, antral follicle development, and characteristics of serum FSH concentrations}

Approximately $24 \mathrm{~h}$ after $\mathrm{PGF}_{2 \alpha}$ treatment on day 8 of the estrous cycle, serum progesterone concentrations declined $(P<0.05)$ to $<1 \mathrm{ng} / \mathrm{ml}$, and remained at low concentrations until the collection of ovaries (Fig. 1A). Follicular fluid $\mathrm{E}_{2}$ concentrations did not differ between preovulatory follicles from the final wave compared with the preovulatory follicles from the penultimate wave $(110.8 \pm 51.6$ vs $100.7 \pm 36.5 \mathrm{ng} / \mathrm{ml}$ respectively).

After $\mathrm{PGF}_{2 \alpha}$ and MAP treatment, preovulatory follicles emerged from both the final and penultimate waves of the cycle (Fig. 1B). The mean days of wave emergence were $8.9 \pm 0.2$ and $13.0 \pm 0.2$ after ovulation for the
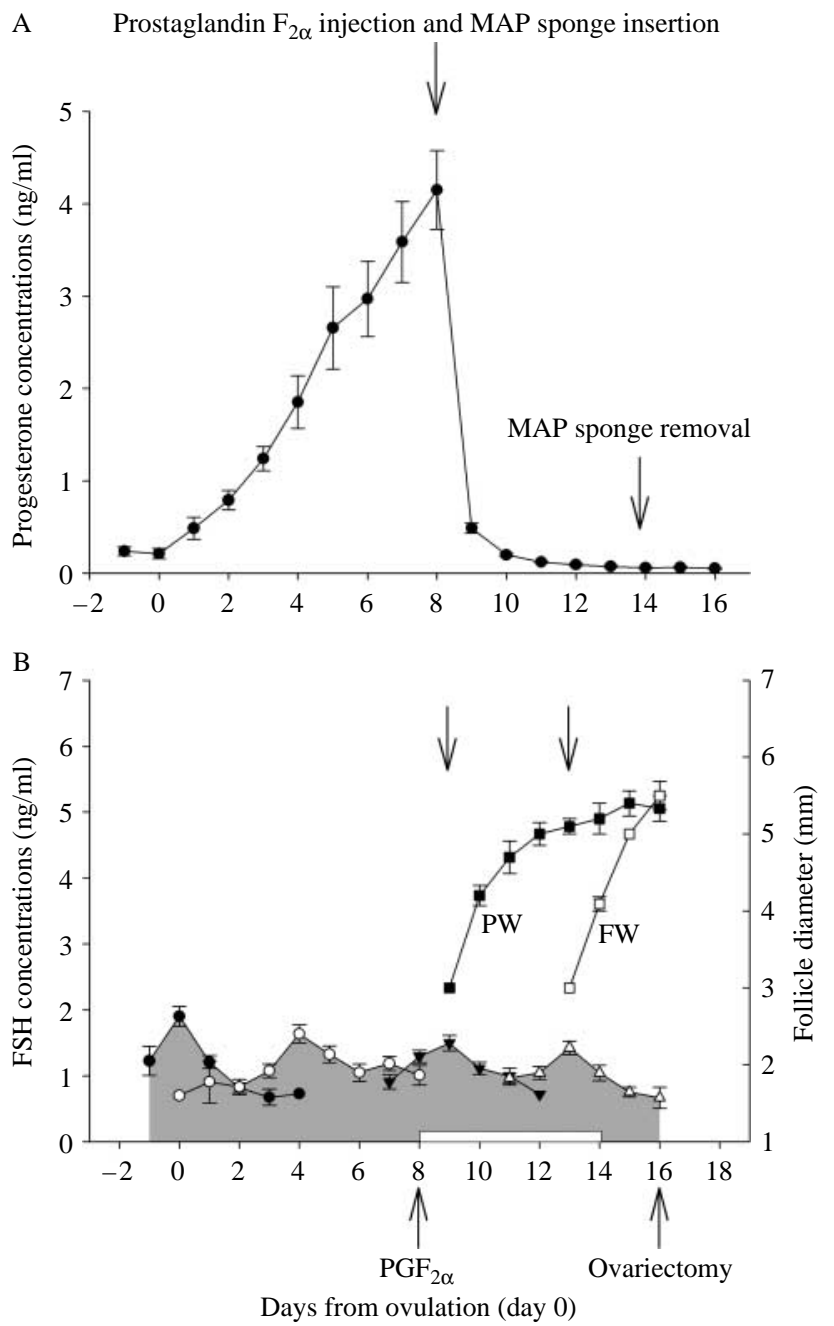

Figure 1 (A) Serum progesterone concentrations throughout the experimental period. Data were normalized to the day of ovulation (day 0). Serum progesterone concentrations on day 0 were $0.2 \pm 0.1 \mathrm{ng} / \mathrm{ml}$. (B) Peaks in serum concentrations of FSH (outlined with shading) and their associated emerging follicular waves in ewes that received a $\mathrm{PGF}_{2 \alpha}$ injection on day 8 and a MAP sponge on day 8; sponges were left in place for 14 days (indicated by the rectangle box on $x$-axis) after ovulation. Data were normalized to the day of ovulation (day 0 ) in all the ewes. Serum FSH concentrations on day 0 were $1.7 \pm 0.2 \mathrm{ng} / \mathrm{ml}$. The average curves representing the growth, static, and regression phases of all the ewes in a group were normalized for each follicle wave to the mean day of wave emergence (indicated by the arrows. All the FSH peaks for all the ewes are shown normalized to the mean day of occurrence of the apex of the FSH peak for each wave. Please note that transrectal ultrasonography was performed initially to detect ovulation at the beginning of the study and from day 8 until ovariectomy to monitor antral follicular development. Therefore, we could only detect the growth patterns of the second to last (penultimate wave (PW; black squares)) and last (final wave (FW; open squares)) wave of the cycle. The FSH peaks triggering the emergence of PW and FW are shown by black triangles and open triangles respectively. The black circles and open circles pertain to the first and second FSH peaks of the cycle respectively. For every FSH peak, serum concentration profiles were delimited by the encompassing nadirs of the FSH concentrations (hence the overlap of the data for adjacent peaks in some cases). 
penultimate and final waves respectively (Fig. 1B). Preovulatory follicles from the penultimate wave had a longer $(P<0.05)$ lifespan compared with the follicles from the final wave $(7.1 \pm 0.2$ vs $3.0 \pm 0.2$ days; $P<0.05$; Fig. 1B). The static phase of preovulatory follicles from the penultimate wave was longer $(P<0.05)$ compared with the follicles from the final wave $(3.6 \pm 0.7$ vs 0.4 \pm 0.2 days; Fig. 1B). However, the growth phase (3.7 \pm 0.6 vs $2.6 \pm 0.9$ days) and the growth rate $(0.9 \pm 0.2$ vs $1.1 \pm 0.1 \mathrm{~mm} /$ day) did not differ among the follicles from the penultimate and the final waves (Fig. 1B). The mean maximum follicle diameter at the time of follicle collection did not differ among the preovulatory follicles from the penultimate $(5.4 \pm 0.2 \mathrm{~mm})$ and the final $(5.55 \pm 0.2 \mathrm{~mm})$ waves (Fig. 1B).

The mean days of the estrous cycle when the FSH peaks triggered the penultimate and final waves were $8.9 \pm 0.3$ and $12.7 \pm 0.3$ respectively (Fig. 1B). There were no differences in FSH peak concentrations, amplitude and duration, or basal FSH concentrations among the peaks that triggered the penultimate and final waves (Fig. 1B).

\section{Immunohistochemical localization and image analysis}

Factor VIII, PCNA, and GJA1 were detected in follicles from the final and the penultimate waves (Fig. 2). Factor VIII was immunolocalized to blood vessels in the theca layer (Fig. 2A and B), but PCNA (Fig. 2C and D) and GJA1 (Fig. 2E and F) were detected in the granulosa and theca layers of ovarian follicles. In all follicles from the penultimate wave, pyknotic nuclei (a marker of early atresia) were detected in the granulosa layer (Fig. 2B, D and $\mathrm{F}$ ). Pyknotic nuclei were not detected in follicles from the final wave (Fig. 2A, C and E).

Expression of factor VIII in the theca layer was greater $(P<0.05)$ in preovulatory follicles from the final wave compared with the follicles from the penultimate wave (Fig. 3A). The $\mathrm{LI}$ in the granulosa cells was greater $(P<0.05)$ and tended to be greater $(P=0.06)$ in the theca cells of preovulatory follicles from the final wave compared with the follicles from the penultimate wave (Fig. 3B). Overall, for preovulatory follicles from the final and penultimate waves combined, $\mathrm{LI}$ tended to be greater $(P=0.06)$ in the granulosa cells than in the theca cells $(25.7 \pm 5.3$ vs $15.3 \pm 4.1 \%$ respectively).
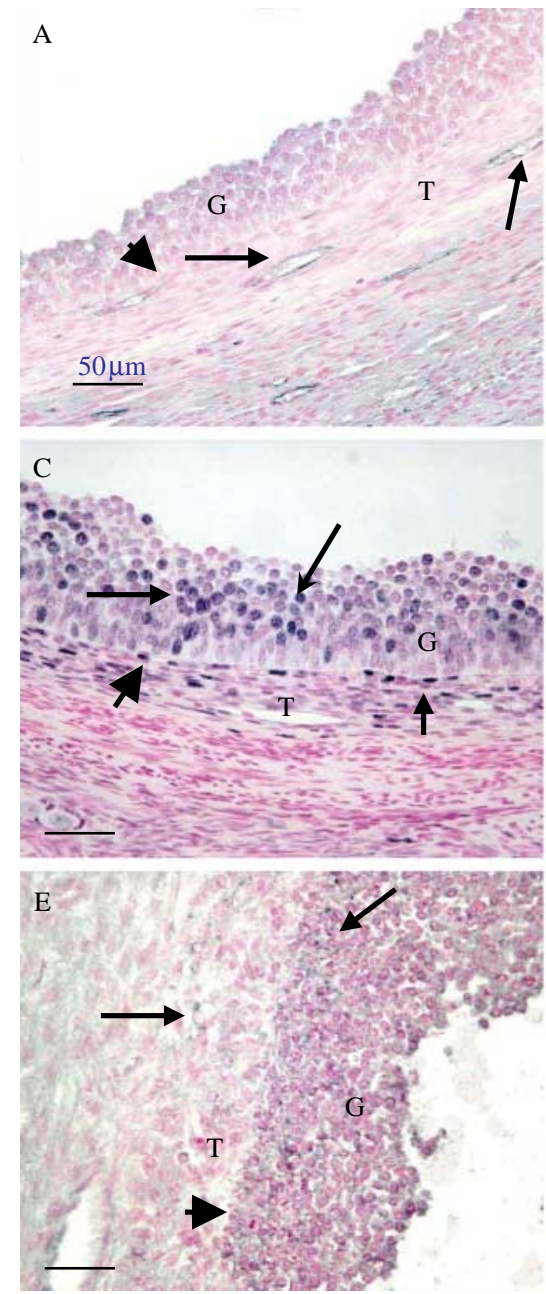
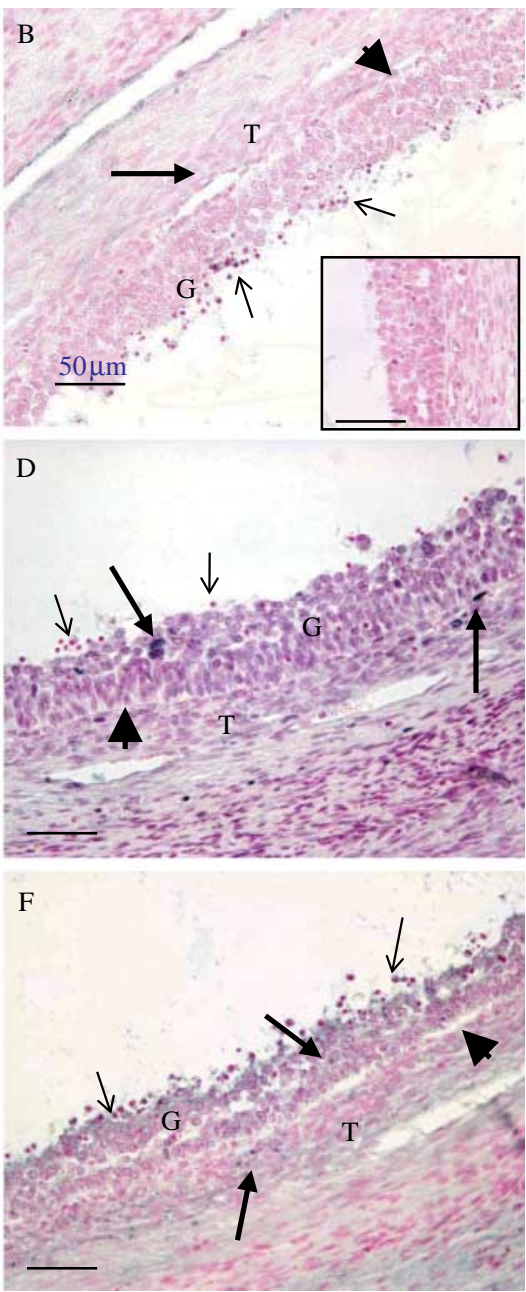

Figure 2 Representative micrographs of immunohistochemical staining for factor VIII (A and B), PCNA ( $C$ and $D$ ), and GJA1 ( $E$ and $F$ ) in preovulatory follicles from the final (left column) and penultimate (right column) waves of the cycle. The dark color (bluish gray or blackish) indicates positive staining (arrows), and pink staining indicates cell nuclei (fast red staining) in the granulosa $(\mathrm{G})$ and theca $(\mathrm{T})$ layers. The large white area is the follicular antrum. Negative controls (insert in B) did not exhibit any staining. Arrowheads identify the basement membrane. Small arrows identify pyknotic nuclei (dark red) in the granulosa layer of follicles from penultimate wave in $B, D$, and $F$. Note the relatively stronger and weaker positive staining in preovulatory follicles from the final and penultimate waves respectively. Size of the bar $=50 \mu \mathrm{m}$. 

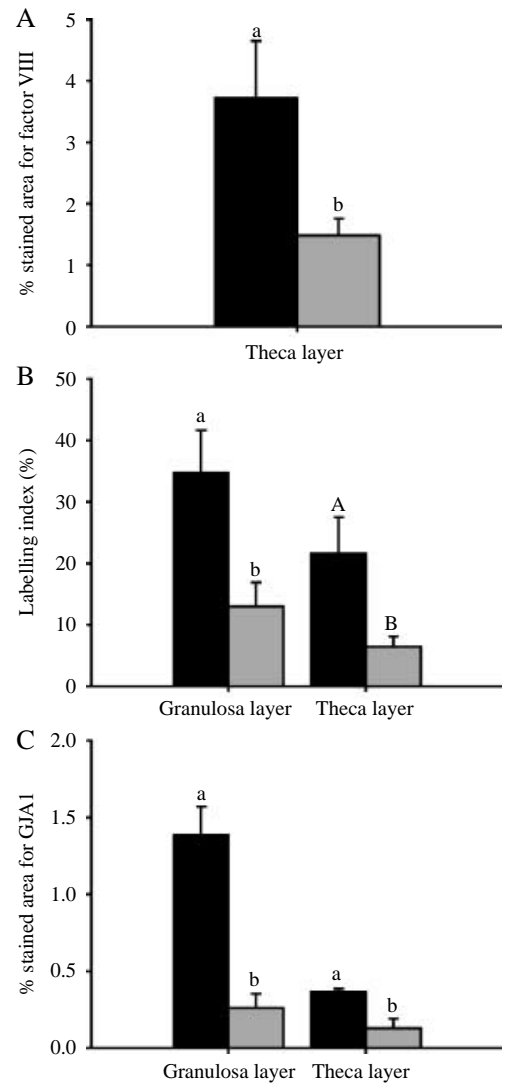

Figure 3 Expression of factor VIII (A), labeling index (B), and expression of GJA1 (C) in the granulosa and theca cells of preovulatory follicles from the final (black bars) and penultimate (gray bars) waves of the estrous cycle. ${ }^{\mathrm{a}, \mathrm{b}} \mathrm{P}<0.05$; for the granulosa and theca layers separately, values with different superscripts differ among follicles from the final and penultimate waves of the cycle. ${ }^{\mathrm{A}, \mathrm{B}} P \leq 0.1$ and $\geq 0.05$; for the granulosa and theca layers separately, values with different superscripts tend to differ among follicles from the final and penultimate waves of the cycle.

GJA1 expression was greater $(P<0.05)$ in both the granulosa and theca cells of preovulatory follicles from the final wave compared with the follicles from the penultimate wave (Fig. 3C).

\section{Apoptosis}

Apoptotic cells and bodies were detected in the granulosa and theca layers in follicles from the final and penultimate waves of the estrous cycle (Fig. 4A and $\mathrm{B}$ ). The percentage of apoptotic (TUNEL-positive) cells for the granulosa and theca layers combined was greater $(P<0.05)$ in preovulatory follicles from the penultimate wave than in the follicles from the final wave $(25.8 \pm 4.0$ vs $7.3 \pm 3.3 \%$ respectively).

\section{Relative mRNA expression}

Expression of VEGF mRNA was greater $(P<0.05)$ in the theca cells and tended to be greater $(P=0.06)$ in the granulosa cells of preovulatory follicles from the final wave compared with the follicles from the penultimate wave (Fig. 5). Expression of NOS3 mRNA tended to be greater $(P=0.06)$ in the theca cells of preovulatory follicles from the final wave compared with the follicles from the penultimate wave (Fig. 5). Expression of NOS3 mRNA in the granulosa cells was similar $(P>0.1)$ in the follicles from the final and penultimate waves (Fig. 5). Expression of GJA1 mRNA was greater $(P<0.05)$ in the granulosa cells and tended to be greater $(P=0.09)$ in the theca cells of preovulatory follicles from the final wave compared with the follicles from the penultimate wave (Fig. 5).

\section{Discussion}

In agreement with previous studies (Johnson et al. 1996, Leyva et al. 1998, Vinoles et al. 1999, Bartlewski et al. 2003), PGF $_{2 \alpha}$ and MAP treatment resulted in the development of more preovulatory follicles from the penultimate wave in addition to the final wave of the cycle. The preovulatory follicles from the penultimate wave had a longer lifespan compared with the follicles from the final wave. The extended follicular lifespan of the follicles from the penultimate wave may not depend on changes in gonadotropin secretion (Bartlewski et al. 2003). The present study demonstrated no differences among any of the characteristics of the FSH peaks that triggered either the penultimate or the final wave of the cycle. It has been suggested that the low serum concentrations of progestagen from MAP sponges exert direct effects on the ovary and affect follicular function (Bartlewski et al. 2003). However, it is interesting that follicles could grow for different lengths of time, to the same size, with similar FSH peak characteristics; this phenomenon warrants further investigation.

In the present study, overall, the expression of markers of vascularization and/or angiogenesis such as factor VIII, VEGF, and NOS3 was greater in preovulatory follicles from the final wave compared with the follicles from the penultimate wave, even though follicle size was similar. Greater NOS3 expression was observed in healthy developing follicles than in atretic follicles in
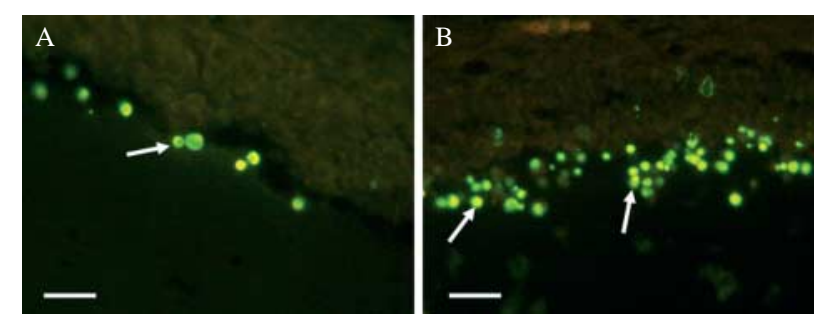

Figure 4 Representative images of apoptosis in preovulatory follicles from final (A) and penultimate (B) waves of the estrous cycle. Note the relatively greater number of apoptotic cells (marked by green fluorescence and arrows) in preovulatory follicles from the penultimate wave than in follicles from the final wave of the cycle. Control staining did not show any positive staining (data not shown). Size of the bar $=50 \mu \mathrm{m}$. 


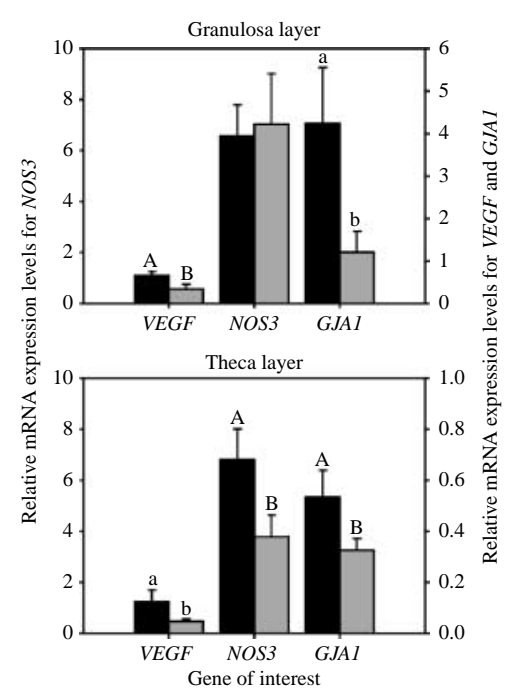

Figure 5 Relative mRNA expression for VEGF, NOS3, and GJA1 in the granulosa (top panel) and theca layers (bottom panel) of preovulatory follicles from the final (black bars) and penultimate waves (gray bars) of the cycle. ${ }^{a, b} P<0.05$; for specific gene, values with different superscripts differ for follicles from the final and penultimate waves.

${ }_{\mathrm{A}, \mathrm{B}} P \leq 0.1$ and $\geq 0.05$; for specific gene, values with different superscripts tend to differ for follicles from the final and penultimate waves.

sheep (Grazul-Bilska et al. 2006). In sheep and cattle, it has been shown that the expression of angiogenic factors such as VEGF and NOS3 is associated with enhanced vascularization of large ovarian antral follicles, which likely contributes to maintaining these follicles in a nonatretic state (Redmer \& Reynolds 1996, Grazul-Bilska et al. 2006, 2007). Both VEGF and NOS3 are major regulators of follicular development in sheep (Hunter et al. 2004, Fraser 2006). The high expression of angiogenic factors and increased vascular surface area, as indicated by factor VIII expression, likely resulted in an enhanced vascular supply and hence enhanced exchange of nutrients, gonadotropins, and growth factors in follicles from the final wave compared with the follicles from the penultimate wave of the cycle, in the present study (Grazul-Bilska et al. 2006, 2007). In fact, it has been demonstrated that vascularity in the theca layer may serve as an indicator of follicle health in several species (Mattioli et al. 2001, Jiang et al. 2003). Even though $\mathrm{PGF}_{2 \alpha}$ and MAP treatment resulted in large ovulatory sized follicles in both the final and penultimate waves of the estrous cycle, the quality of the follicles from the penultimate wave was compromised with respect to vascularization and angiogenesis compared with the follicles from the final wave.

In the present study, proliferative activity of the granulosa and theca cells, as detected by expression of PCNA, was greater in follicles from the final wave compared with the follicles from the penultimate wave of the cycle. In cattle, it has been shown that cellular proliferation in the granulosa and theca layers was greater in estrogen-active and dominant follicles than in estrogen-inactive and non-dominant follicles (GrazulBilska et al. 2007). In addition, a greater proliferation rate was observed in healthy follicles compared with the atretic follicles in sheep and cattle (Jablonka-Shariff et al. 1994, Isobe \& Yoshimura 2000). In the present study, apoptosis was greater in follicles from the penultimate wave than in follicles from the final wave. Apoptosis is a marker of atresia in ovarian follicles (Hussein 2005, Krysko et al. 2008). Therefore, the high rate of apoptosis and appearance of pyknotic nuclei in follicles from the penultimate wave in the present study indicate that atresia was initiated in these follicles. However, we did not observe a decrease in $E_{2}$ concentration in follicular fluid from follicles of the penultimate wave. This may be due to very early stage of atresia observed for these follicles (as documented by morphology in Fig. 2). Therefore, at this stage of atresia, a decline in $E_{2}$ production is likely only initiated, and a relatively high level of $E_{2}$ is still present in follicular fluid. In contrast, decrease in follicular fluid concentration of $E_{2}$ and aromatase activity in the granulosa cells has been shown as apoptosis progressed during early atresia of ovarian follicles in the ewe (Jolly et al. 1997). The differences between Jolly et al. (1997) and our studies are likely due to the different animal treatment causing initiation of atresia (e.g. injections of steroid-free bovine follicular fluid versus hormonal treatment respectively) and breed. Thus, these data led us to conclude that in follicles from the penultimate wave with an extended static phase, there is a decrease in the granulosa and theca cell proliferation and enhanced apoptosis leading to follicle atresia, and likely poor oocyte quality.

Both the protein and mRNA expression for GJA1 were greater in follicles from the final wave compared with the follicles from the penultimate wave in the present study. The importance of GJA1, the major gap junctional protein in ovaries, during follicular development is well recognized (Grazul-Bilska et al. 1997, Kidder \& Mhawi 2002, Gershon et al. 2008). Gap junctions are required for the granulosa and theca cell proliferation, steroidogenesis, signal transduction, and cell survival (GrazulBilska et al. 1997, Kidder \& Mhawi 2002). Based on studies in knockout mice, it was shown that intracellular coupling between the granulosa cells is decreased in ovaries lacking GJA1 leading to a decreased follicular growth, an increased apoptosis of granulosa cells, and a lack of ovulation (Ackert et al. 2001, Gittens et al. 2005). In addition, it has been shown that the level of GJA1 mRNA expression in human preovulatory follicles or the bovine cumulus-oocyte complex predicts oocyte developmental competence (Calder et al. 2003, Tsai et al. 2003). Moreover, decreased expression of GJA1 was observed in atretic follicles in sheep and cattle (Grazul-Bilska et al. 1998, Johnson et al. 1999). Therefore, GJA1 appears to be critical for follicular development and thus can be used as a marker for follicle 
quality. In the present study, due to low expression of GJA1, gap junctional communication was likely limited within the granulosa and theca cells of follicles from the penultimate wave compared with the follicles from the final wave of the cycle, probably compromising oocyte quality.

One of the primary goals in controlled sheep breeding is to increase the number of live births from an ewe. A field study utilizing the treatment used in the present study did not improve the fertility rate, even though there was an increased ovulation rate (Davies 2005). The findings of the present study clearly show that the inability of the $\mathrm{PGF}_{2 \alpha}$ and MAP treatment to increase fertility could be partly due to a decrease in the quality of preovulatory follicles from the penultimate wave of the estrous cycle, whose lifespan was extended (Bartlewski et al. 2003). However, although significant differences between follicles from the final and penultimate waves of the cycle in the present study were clearly demonstrated, one note of caution in interpretation should be added. We were unable to observe how many follicles ovulated, but in our original study (Bartlewski et al. 2003), 21\% more follicles ovulated from the pool of ovulatory sized follicles from the final wave compared with the follicles from the penultimate wave of the cycle in ewes that received the same treatment as in the present study. In addition, in the present study, the collection of follicles likely occurred around the time of the preovulatory $\mathrm{LH}$ surge (Bartlewski et al. 2003). Therefore, some of the differences that we noted between follicles from the final and penultimate waves could have reflected differential responses to the $\mathrm{LH}$ surge. In cattle, when the estrous cycle is extended by low levels of progesterone, follicles growing in a wave have a longer lifespan, reach a greater diameter, and appear to produce more $\mathrm{E}_{2}$ (Sirois \& Fortune 1990). Oocyte quality is compromised in older follicles in cattle, and fertility is decreased (Austin et al. 1999, Mihm et al. 1999). Ovulation of dominant follicles with a prolonged lifespan in cattle leads to early embryonic loss as a result of altered expression of genes that are important for transcription and translation in the oocyte (Lingenfelter et al. 2007). In cattle, oocytes from the dominant follicles with a prolonged lifespan undergo premature maturation leading to decreased fertility (Revah \& Butler 1996). In contrast, Evans et al. (2001) demonstrated that ovine oocytes from follicles with a prolonged lifespan could be fertilized and produce good quality embryos. The discrepancies above are likely due to different hormonal treatments and/or species. Hormonal treatments should be optimized to enhance follicular development from the penultimate wave of a cycle, in the ewe that would also enhance fertility and/or fecundity.

In summary, $\mathrm{PGF}_{2 \alpha}$ and MAP treatment gave rise to preovulatory follicles emerging from both the final and penultimate waves of the cycle in WWF ewes. Follicles from the penultimate wave had a longer lifespan and static phase compared with follicles from the final wave.
Vascularization, cell proliferation, and expression of angiogenic factors and gap junctional protein GJA1 were greater in preovulatory follicles from the final wave compared with follicles from the penultimate wave. This indicates that although the treatment with $\mathrm{PGF}_{2 \alpha}$ and MAP enhanced ovulation rate by extending the lifespan of follicles in the penultimate wave, these follicles were not as functionally viable as follicles in the final wave. $\mathrm{PGF}_{2 \alpha}$ and MAP treatment provides a useful model to study aged antral follicles and oocytes, but this treatment is not useful for enhancing fecundity.

\section{Materials and Methods}

\section{Animals, ultrasound technique and blood sampling}

Care and handling of experimental animals was carried out according to the Canadian Council on Animal Care's published guidelines. Sexually mature, healthy, cycling, WWF ewes (Ovis aries; $n=15$; mean body weight of $83.34 \pm 2.3 \mathrm{~kg}$ ) were housed indoors for the duration of the study (Saskatoon, SK, Canada; latitude: $52^{\circ} 10^{\prime} \mathrm{N}$ ). The experiment was performed during the breeding season (December-January), and day length was set to ambient, outdoor conditions. Ewes were fed a maintenance diet of hay with free access to cobalt iodized saltlicks and water. Ewes were monitored daily for estrus with vasectomized crayon marker-harnessed rams.

Ovarian antral follicular dynamics was monitored daily (starting at $0800 \mathrm{~h}$ ) in all the ewes by transrectal ovarian ultrasonography (scanning) using a $7.5 \mathrm{MHz}$ transducer stiffened with a hollow plastic rod and connected to a B-mode, real-time echo camera (Aloka SSD-900, Overseas Monitor, Richmond, BC, Canada). This technique can be used to accurately quantify ovarian antral follicles $\geq 2 \mathrm{~mm}$ in diameter and detect corpora lutea in sheep (Duggavathi et al. 2003). All images were viewed at a magnification of $\times 1.5$ with constant gain and focal point settings. Ovarian images were recorded (Panasonic AG 1978, Matsushita Electric, Mississauga, ON, Canada) on high-grade video tapes (Fuji S-VHS, ST-120 N, Fujifilm, Tokyo, Japan) for later examination. The relative position and dimension of follicles and luteal structures were also sketched on ovarian charts.

Blood samples $(10 \mathrm{ml})$ were collected daily after scanning by jugular venipuncture, using vacutainers (Becton Dickinson, Franklin Lakes, NJ, USA). All the samples were permitted to clot at room temperature for 18-24 h. Samples were then centrifuged for $10 \mathrm{~min}$ at $1500 \mathrm{~g}$, and serum was removed and stored at $-20{ }^{\circ} \mathrm{C}$ until assayed for progesterone and $\mathrm{FSH}$ concentrations.

\section{Analysis of follicular data}

A follicular wave consisted of a follicle or a group of follicles that emerged and grew from 2 to $3 \mathrm{~mm}$ in diameter to $\geq 5 \mathrm{~mm}$ in diameter (growth phase), before regressing to $2-3 \mathrm{~mm}$ in diameter (regression phase) or ovulation; the period over which a follicle was maintained at a size of $\geq 5 \mathrm{~mm}$ was regarded as the static phase (Bartlewski et al. 1999). The length of the growth and static phases, growth rate, and life span of 
the largest follicle growing in the penultimate and final waves were analyzed. The lifespan of a large antral follicle was defined as the interval from its emergence at a diameter of 2 or $3 \mathrm{~mm}$ to the day of follicle collection.

\section{Experimental design, tissue collection, and tissue preparation}

For all sheep, transrectal ovarian ultrasonography was performed to detect ovulation and was continued to monitor ovarian antral follicular growth from day 8 after ovulation until ovariectomy 8 days later. Starting on day 8 of the estrous cycle (day 0 was the day of ovulation), all the ewes were administered a single injection of $\mathrm{PGF}_{2 \alpha}$ (15 mg i.m.; Lutalyse; Upjohn, Orangeville, ON, Canada) and an intravaginal MAP sponge (60 mg; Veramix; Upjohn), which remained in place for 6 days.

After removal of the sponge, we could clearly identify and monitor the development of large ovulatory follicles $(\geq 5 \mathrm{~mm}$ in diameter) from both the penultimate wave and the final wave of the cycle. A map of ovarian follicular growth with time was created to allow us to identify the type of follicles collected. Two days after sponge removal, the ovaries that contained large preovulatory follicle(s) growing in the penultimate and final waves were collected by ovariectomy. Ovariectomy was performed by mid-ventral laparotomy within 5 min after killing by Euthanyl Forte (i.v.; $1 \mathrm{ml} / 5 \mathrm{~kg}$ of body weight; Bimeda-MTC Animal Health Inc., Cambridge, ON, Canada). The ovaries were collected prior to ovulation which occurs $\sim 72 \mathrm{~h}$ after the sponge removal, but just at the time of the onset of the preovulatory LH surge that starts about $48 \mathrm{~h}$ after the sponge removal (Bartlewski et al. 2003). Out of 15 ewes, ovaries from eight ewes were used for gene expression studies and ovaries from seven ewes were used for protein expression studies. All the ewes had one follicle each from the final and penultimate waves of the cycle except for one ewe each in the gene expression and protein expression study groups which had two follicles from each of the final and penultimate waves respectively.

Ovaries were collected and processed for the protein and mRNA expression as described previously (Grazul-Bilska et al. 1998, 2006, Borowczyk et al. 2006). Briefly, the ovaries were placed on ice and immediately transferred to the laboratory. The ovaries were washed using cold PBS solution containing $2 \%$ streptomycin and penicillin (Sigma), to remove blood from the ovarian surface. The ovaries were then placed on ice in a 60-mm petri dish containing tissue culture medium-199 (TCM-199; Gibco), supplemented with $1 \%$ penicillin and streptomycin (Sigma), and surface diameter of preovulatory follicles was measured.

For the protein expression studies, the ovaries were cut into small pieces which contained the identified follicle. Each follicle was split up between two different fixation protocols. A portion of ovary containing half of a follicle was fixed in Carnoy's solution (6 parts of ethyl alcohol, 3 parts of chloroform, and 1 part of glacial acetic acid) for 2-4 h, and another portion of ovary containing another half of a follicle was fixed in $4 \%$ paraformaldehyde for $24 \mathrm{~h}$ at room temperature (in total, seven follicles from the final wave and eight follicles from the penultimate wave). Fixed tissues were dehydrated using graded series of ethanol and cleared with a histological clearing agent (Histoclear, National Diagnostics, Atlanta, GA, USA). The tissues were embedded in paraffin, and then 4- $\mu \mathrm{m}$ sections were cut and mounted onto poly-L-Lysine coated slides for immunohistochemical staining. One section per ovary containing the respective follicles was used for immunohistochemistry and for generating five to ten images for image analysis.

For the mRNA expression studies, the granulosa and theca cells from the follicles were collected separately as described previously (Borowczyk et al. 2006). Follicular fluid from preovulatory follicles from the penultimate and final waves was aspirated and centrifuged to sediment the granulosa cells. The follicle was then flushed with TCM-199 media in order to maximize the yield of granulosa cells. The theca cell layer was dissected from the follicle wall using fine tissue forceps. The granulosa and theca layers from the final and penultimate waves for each sheep were suspended separately in PBS and stored at $-80^{\circ} \mathrm{C}$ until used for mRNA extraction.

\section{Hormone analysis}

Progesterone (Rawlings et al. 1984) and FSH (Currie \& Rawlings 1989) concentrations in serum samples and $E_{2}$ concentrations (Evans et al. 2004) in follicular fluid were measured by validated RIA procedures. For follicular fluid $E_{2}$ evaluation, follicular fluid from the preovulatory follicles was diluted 1:5000 prior to the assay. The assay sensitivities (defined as the lowest concentration of a hormone capable of significantly displacing radiolabeled hormone from the antibody) were $0.03 \mathrm{ng} / \mathrm{ml}$ for progesterone, $0.1 \mathrm{ng} / \mathrm{ml}$ for $\mathrm{FSH}$, and $5.0 \mathrm{pg} / \mathrm{ml}$ for $\mathrm{E}_{2}$. The ranges of standards were $0.1-5$ and $0.12-16.0 \mathrm{ng} / \mathrm{ml}$, for the serum progesterone and $\mathrm{FSH}$ assays respectively, and $5.0-1000 \mathrm{pg} / \mathrm{ml}$ for follicular fluid $\mathrm{E}_{2}$ assay. A concentration equivalent to the sensitivity of the assay was assigned to serum samples with hormone concentrations lower than the assay sensitivity.

The intra- and inter-assay coefficients of variation (CV) were 11.4 and 9.6 or 7.1 and $13.7 \%$ for reference sera with mean progesterone concentrations of 0.26 or $1.17 \mathrm{ng} / \mathrm{ml}$ respectively. The intra-assay CV were 2.2 or $4.0 \%$ for reference sera with mean FSH concentrations of 1.57 or $3.68 \mathrm{ng} / \mathrm{ml}$ respectively. The intra-assay CV were 9.3 or $5.0 \%$ for reference follicular fluid samples with mean $\mathrm{E}_{2}$ concentrations of 18.8 or $216.1 \mathrm{pg} / \mathrm{ml}$ respectively.

Peaks of FSH in the blood samples collected daily were identified using cycle-detection software (Clifton \& Steiner 1983). A fluctuation or cycle was defined as a progressive rise and fall in hormone concentrations that encapsulated a peak concentration (nadir-to-peak-to-nadir; Clifton \& Steiner 1983). Mean basal FSH concentrations were determined by averaging the lowest points between peaks (nadirs). FSH peak concentration was defined as the concentration of FSH observed at the apex of the FSH peak. FSH peak amplitude was defined as the difference between the FSH peak concentration and the nadir before the peak concentration. FSH peak duration was defined as the interval between the two nadirs encompassing the FSH peak. 


\section{Immunohistochemistry}

Detection of factor VIII, PCNA, and GJA1 was performed as described previously (Grazul-Bilska et al. 1998, 2006, 2007, 2009, Pant et al. 2005). Briefly, ovarian tissue sections were deparaffinized, rehydrated, and incubated with $3 \% \mathrm{H}_{2} \mathrm{O}_{2}$ in methanol to eliminate endogenous peroxidase activity. The sections were then rinsed several times in PBS containing Triton $\mathrm{X}-100(0.3 \%, \mathrm{v} / \mathrm{v})$. Then, to block non-specific binding of antibodies, the sections were treated for $20 \mathrm{~min}$ with PBS containing either normal goat serum $(1 \%$, v/v; Vector Laboratories, Burlingame, CA, USA) for factor VIII and GJA1 staining or normal horse serum $(3 \%, \mathrm{v} / \mathrm{v} ; \mathrm{ABC}$ kit, Vector Laboratories) for PCNA staining. The sections were incubated overnight at $4{ }^{\circ} \mathrm{C}$ in PBS containing a primary antibody against factor VIII (1:100; rabbit polyclonal; Sigma), PCNA (1:500; mouse monoclonal; Chemicon International, Temecula, CA, USA), or GJA1 (1:500; rabbit polyclonal; Grazul-Bilska et al. 1998, Pant et al. 2005).

Primary antibodies were detected using a biotin-labeled secondary antibody (anti-rabbit antibody for factor VIII and GJA1; anti-mouse antibody for PCNA; Vector Laboratories) and the avidin biotinylated HRP macromolecular complex (Vector Laboratories). The color was developed using the SG substrate (Vector SG substrate kit, Vector Laboratories).

For GJA1 and factor VIII controls, the primary antibody was replaced with normal rabbit IgG (diluted 1:100), and for PCNA controls, the primary antibody was replaced with normal mouse $\operatorname{lgG}(4 \mu \mathrm{g} / \mathrm{ml})$. After immunostaining, the tissue sections were counter-stained with nuclear fast red to visualize the nuclei.

\section{Image analysis}

For all the ovaries, images of the stained sections $\left(0.025 \mathrm{~mm}^{2}\right.$ per field) were taken for each of the identified follicles from the final and the penultimate waves (total 5-10 images/follicle). The images were then used for quantitative image analysis using the Image-Pro Plus software (Media Cybernetics Inc., Silver Spring, MD, USA). Then, we determined the area that exhibited positive staining for factor VIII (occupied by endothelial cells) in the theca layer; or for GJA1 per tissue area for the granulosa and theca layers separately; and the $\mathrm{LI}$ (calculated as a percentage of proliferating cells out of the total cells per marked area of follicle) for the granulosa and theca cells separately, as described previously (Grazul-Bilska et al. 2007, 2009).

\section{TUNEL assay}

A TUNEL (in situ cell death detection kit AP; Roche Diagnostics Co.) was used to identify the extent of cell apoptosis in the granulosa and theca layers of the collected follicles. The procedure of labeling DNA fragments used in this study was a modification of the protocol described by Weber et al. (2002). For permeabilization, deparaffinized and rehydrated tissue sections were irradiated with microwaves at $800 \mathrm{~W}$ for $90 \mathrm{~s}$ (Kenmore Microwave Oven 1000 W, Model no: 87103, Sears Canada Inc., Toronto, ON, Canada) with $0.1 \mathrm{M}$ citrate buffer
(Sigma). After $3^{\prime}$-end labeling of the DNA fragments and blocking the slides with $3 \%$ BSA in Tris buffer saline, the samples were analyzed in a drop of PBS under a fluorescence microscope (Zeiss Axioskop 40, Carl Zeiss Canada Ltd, Toronto, ON, Canada) using a standard filter (520 nm, green). Every TUNEL assay included a separate positive control slide that was incubated with $1 \mu \mathrm{g} / \mathrm{ml}$ DNase (DNase I recombinant, Roche Diognostics Co.) for $10 \mathrm{~min}$ at $22{ }^{\circ} \mathrm{C}$. Negative control slides were incubated with $50 \mu \mathrm{l}$ label solution without terminal transferase for $60 \mathrm{~min}$ at $37^{\circ} \mathrm{C}$.

The sections that were stained with TUNEL or hematoxylin and eosin were subjected to blinded evaluation. The number of TUNEL-positive and the total number of follicular somatic cells were counted in ten different fields at $1000 \times$ magnification. TUNEL-positive cells were expressed as a percentage of the total number of follicular somatic cells, for the granulosa and theca layers combined.

\section{RNA isolation and quantitative real-time RT-PCR}

Total cellular RNA (tcRNA) was isolated from the granulosa and theca cells using the illustra RNAspin Mini RNA Isolation kit (GE Healthcare UK Ltd, Amersham Place, Buckinghamshire, UK) according to the manufacturers' recommendations. The quantity and quality of tcRNA samples were determined via capillary electrophoresis using an Agilent 2100 Bioanalyzer (Agilent Technologies, Palo Alto, CA, USA). The RNA samples were reverse transcribed in triplicate with $20 \mu \mathrm{l}$ reaction volume containing equal amount of tcRNA for each sample $(1.5 \mathrm{ng} / \mu \mathrm{l})$ using TaqMan RT Reagents (Applied Biosystems, Foster City, CA, USA) as described previously (Redmer et al. 2005, Johnson et al. 2006). All cDNAs from the RT reaction were stored at $-20{ }^{\circ} \mathrm{C}$ prior to PCR analysis.

Expression of mRNA for VEGF, NOS3, and GJA1 in the granulosa and theca cells were determined in the triplicate on the RT samples described above using the ABI PRISM 7000 Sequence Detection system and software as described previously (Redmer et al. 2005, Borowczyk et al. 2006). For each gene assayed, a no-template control was present in duplicate on each real-time RT-PCR plate. The sequences of the primers and probes that were used for each gene studied have been published (Redmer et al. 2005, Borowczyk et al. 2006, Johnson et al. 2006). The primers and probes were designed from species-specific sheep mRNA sequences using the primer express software version 2 (Applied Biosystems). For standard curves, cDNAs from placentomes (for VEGF and NOS3) at day 130 of pregnancy or from ovine heart (for GJA1) were used. Expression of each gene was normalized to the expression of $18 \mathrm{~S}$ rRNA in a multiplex reaction using the human $18 \mathrm{~S}$ predeveloped assay reagent (PDAR) from Applied Biosystems. The PDAR solution, which is primer limited and contains a VIClabeled probe, was further adjusted by one-fourth the normal amount, so that it would not interfere with amplification of the FAM-labeled gene of interest. Standard curves were also generated with the multiplex solution, and the quantity of $18 \mathrm{~S}$ rRNA and the gene of interest was determined using each specific standard curve. The concentrations of mRNA were then normalized to $18 \mathrm{~S}$ rRNA by dividing each of the mRNA 
values by their corresponding $18 \mathrm{~S}$ rRNA value (Redmer et al. 2005, Johnson et al. 2006).

Twelve and one-half microliter final reaction volumes were prepared in 96-well PCR plates fitted with optical adhesive covers (ABI prism, Applied Biosystems) using the TaqMan universal PCR master mix (Applied Biosystems). The samples were heated to $60{ }^{\circ} \mathrm{C}$ for $2 \mathrm{~min}$, then $95^{\circ} \mathrm{C}$ for $10 \mathrm{~min}$, before 40-45 cycles of $15 \mathrm{~s}$ at $95^{\circ} \mathrm{C}$ followed by $1 \mathrm{~min}$ at $60^{\circ} \mathrm{C}$ as per the manufacturer's instructions. The relative standard curve method was used to analyze the real-time RT-PCR data (Johnson et al. 2006).

\section{Statistical analyses}

One-way repeated measures ANOVA (Sigma Stat 7 for Windows Version 2.03, 1997, SPSS Inc., Chicago, IL, USA) was used to assess differences in characteristics of FSH peaks (i.e. FSH peak concentrations and amplitude, FSH peak duration, and basal FSH concentrations) among peaks during the experimental period studied. The $t$-test was used to compare the characteristics of ovarian follicles (i.e. length of the growth and static phases, growth rate, and life span) among the penultimate and final wave follicles. The $t$-test was also used to compare the relative mRNA expression and protein expression levels in the granulosa and theca cells of preovulatory follicles from the final and penultimate waves. The percentage of apoptotic cells in follicles originating from the penultimate or the final wave of the estrous cycle was compared by Wilcoxon signed-rank test (Statistix Statistical Software for Windows, Version 8, Analytical Software, Tallahassee, FL, USA). Data are expressed as mean \pm s.E.M. Statistical significance was defined as $P<0.05$. A tendency for a statistical significance was defined as $P \geq 0.05$ and $P \leq 0.1$.

\section{Declaration of interest}

The authors declare that there is no conflict of interest that could be perceived as prejudicing the impartiality of the research reported.

\section{Funding}

This work was supported by the Natural Sciences and Engineering Research Council (NSERC), Canada, to N C Rawlings, IDeA Network of Biomedical Research Excellence (INBRE) program of the National Center for Research Resources, and North Dakota Hatch project, ND01712, to A T Grazul-Bilska. S V Seekallu and B M Toosi were the recipients of University of Saskatchewan Graduate Student Scholarships.

\section{Acknowledgements}

The authors thank Dr A F Parlow of NIDDK/NHPP for the provision of reagents for the FSH assay. We thank Ms Susan J Cook, Noreen Rapin, and Kim Tran for their help in RIA and RNA isolations. We also thank Drs Carl Lessard and Kosala Rajapaksha for their help in the granulosa and theca cell isolations. We thank Dr Mary Lynn Johnson and Mr Kim Kraft for their expert help in RT-PCR and immunohistochemistry respectively. We thank Drs Redmer and Reynolds for their valuable comments and suggestions during the preparation of this manuscript. We thank the animal care unit of the Western College of Veterinary Medicine, University of Saskatchewan, for their excellent care and management of the sheep.

\section{References}

Ackert CL, Gittens JE, O’Brien MJ, Eppig JJ \& Kidder GM 2001 Intercellular communication via connexin 43 gap junctions is required for ovarian folliculogenesis in the mouse. Developmental Biology 233 258-270. (doi:10.1006/dbio.2001.0216)

Austin EJ, Mihm M, Ryan MP, Williams DH \& Roche JF 1999 Effect of duration of dominance of the ovulatory follicle on onset of estrus and fertility in heifers. Journal of Animal Science 77 2219-2226.

Bartlewski PM, Beard AP, Cook SJ, Chandolia RK, Honaramooz A \& Rawlings NC 1999 Ovarian antral follicular dynamics and their relationships with endocrine variables throughout the oestrous cycle in breeds of sheep differing in prolificacy. Journal of Reproduction and Fertility 115 111-124. (doi:10.1530/jrf.0.1150111)

Bartlewski PM, Duggavathi R, Aravindakshan J, Barrett DM, Cook SJ \& Rawlings NC 2003 Effects of a 6-day treatment with medroxyprogesterone acetate after prostaglandin $\mathrm{F}_{2 \alpha}$-induced luteolysis at midcycle on antral follicular development and ovulation rate in nonprolific western white-faced ewes. Biology of Reproduction 68 1403-1412. (doi:10. 1095/biolreprod.102.007278)

Borowczyk E, Johnson ML, Bilski JJ, Borowicz PP, Redmer DA, Reynolds LP \& Grazul-Bilska AT 2006 Expression of gap junctional connexins 26, 32, and 43 mRNA in ovarian preovulatory follicles and corpora lutea in sheep. Canadian Journal of Physiology and Pharmacology $\mathbf{8 4}$ 1011-1020. (doi:10.1139/Y06-054)

Calder MD, Caveney AN, Smith LC \& Watson AJ 2003 Responsiveness of bovine cumulus-oocyte-complexes (COC) to porcine and recombinant human $\mathrm{FSH}$, and the effect of COC quality on gonadotropin receptor and Cx43 marker gene mRNAs during maturation in vitro. Reproductive Biology and Endocrinology 1 14. (doi:10.1186/1477-7827-1-14)

Clifton DK \& Steiner RA 1983 Cycle detection: a technique for estimating the frequency and amplitude of episodic fluctuations in blood hormone and substrate concentrations. Endocrinology 112 1057-1064. (doi:10. 1210/endo-112-3-1057)

Currie WD \& Rawlings NC 1989 Fluctuation in responsiveness of LH and lack of responsiveness of FSH to prolonged infusion of morphine and naloxone in the ewe. Journal of Reproduction and Fertility 86 359-366. (doi:10.1530/jrf.0.0860359)

Davies KL 2005 Ovarian antral follicular dynamics and regulation in sheep. Thesis University of Saskatchewan, Saskatchewan, Canada.

Duggavathi R, Bartlewski PM, Barrett DM \& Rawlings NC 2003 Use of high-resolution transrectal ultrasonography to assess changes in numbers of small ovarian antral follicles and their relationships to the emergence of follicular waves in cyclic ewes. Theriogenology 60 495-510. (doi:10. 1016/S0093-691X(03)00041-4)

Evans AC, Flynn JD, Quinn KM, Daffy P, Quinn P, Madgwick S, Crosby TF, Bolan MP \& Beard AP 2001 Ovulation of aged follicles does not affect embryo quality or fertility after a 14-day progestagen estrus synchronization protocol in ewes. Theriogenology 56 923-936. (doi:10.1016/S0093691X(01)00619-7)

Evans AC, Ireland JL, Winn ME, Lonergan P, Smith GW, Coussens PM \& Ireland JJ 2004 Identification of genes involved in apoptosis and dominant follicle development during follicular waves in cattle. Biology of Reproduction 70 1475-1484. (doi:10.1095/biolreprod.103.025114)

Fraser HM 2006 Regulation of the ovarian follicular vasculature. Reproductive Biology and Endocrinology 4 18. (doi:10.1186/14777827-4-18)

Gershon E, Plaks V \& Dekel N 2008 Gap junctions in the ovary: expression, localization and function. Molecular and Cellular Endocrinology 282 18-25. (doi:10.1016/j.mce.2007.11.001) 
Ginther OJ, Kot K \& Wiltbank MC 1995 Associations between emergence of follicular waves and fluctuations in $\mathrm{FSH}$ concentrations during the estrous cycle in ewes. Theriogenology 43 689-703. (doi:10.1016/0093691X(94)00074-5)

Gittens JE, Barr KJ, Vanderhyden BC \& Kidder GM 2005 Interplay between paracrine signaling and gap junctional communication in ovarian follicles. Journal of Cell Science 118 113-122. (doi:10.1242/jcs.01587)

Grazul-Bilska AT, Reynolds LP \& Redmer DA 1997 Gap junctions in the ovaries. Biology of Reproduction 57 947-957. (doi:10.1095/biolreprod57.5.947)

Grazul-Bilska AT, Redmer DA, Bilski JJ, Jablonka-Shariff A, Doraiswamy V \& Reynolds LP 1998 Gap junctional proteins, connexin 26, 32, and 43 in sheep ovaries throughout the estrous cycle. Endocrine 8 269-279. (doi:10.1385/ENDO:8:3:269)

Grazul-Bilska AT, Navanukraw C, Johnson ML, Arnold DA, Reynolds LP \& Redmer DA 2006 Expression of endothelial nitric oxide synthase in the ovine ovary throughout the estrous cycle. Reproduction 132 579-587. (doi:10.1530/REP-06-0009)

Grazul-Bilska AT, Navanukraw C, Johnson ML, Vonnahme KA, Ford SP, Reynolds LP \& Redmer DA 2007 Vascularity and expression of angiogenic factors in bovine dominant follicles of the first follicular wave. Journal of Animal Science 85 1914-1922. (doi:10.2527/jas.2007-0044)

Grazul-Bilska AT, Caton JS, Arndt W, Burchill K, Thorson C, Borowczyk E, Bilski JJ, Redmer DA, Reynolds LP \& Vonnahme KA 2009 Cellular proliferation and vascularization in ovine fetal ovaries: effects of under nutrition and selenium in maternal diet. Reproduction 137 699-707. (doi:10.1530/REP-08-0375)

Hunter MG, Robinson RS, Mann GE \& Webb R 2004 Endocrine and paracrine control of follicular development and ovulation rate in farm species. Animal Reproduction Science 82-83 461-477. (doi:10.1016/j. anireprosci.2004.05.013)

Hussein MR 2005 Apoptosis in the ovary: molecular mechanisms. Human Reproduction Update 11 162-178. (doi:10.1093/humupd/dmi001)

Isobe $\mathbf{N} \&$ Yoshimura $\mathbf{Y} 2000$ Immunocytochemical study of cell proliferation in the cystic ovarian follicles in cows. Theriogenology 54 1159-1169. (doi:10.1016/S0093-691X(00)00423-4)

Jablonka-Shariff A, Fricke PM, Grazul-Bilska AT, Reynolds LP \& Redmer DA 1994 Size, number, cellular proliferation, and atresia of gonadotropininduced follicles in ewes. Biology of Reproduction 51 531-540. (doi:10. 1095/biolreprod51.3.531)

Jiang JY, Macchiarelli G, Tsang BK \& Sato E 2003 Capillary angiogenesis and degeneration in bovine ovarian antral follicles. Reproduction 125 211-223. (doi:10.1530/rep.0.1250211)

Johnson SK, Dailey RA, Inskeep EK \& Lewis PE 1996 Effect of peripheral concentrations of progesterone on follicular growth and fertility in ewes. Domestic Animal Endocrinology 13 69-79. (doi:10.1016/07397240(95)00045-3)

Johnson ML, Redmer DA, Reynolds LP \& Grazul-Bilska AT 1999 Expression of gap junctional proteins connexin 43, 32, and 26 throughout follicular development and atresia in cows. Endocrine 10 43-51. (doi:10.1385/ ENDO:10:1:43)

Johnson ML, Grazul-Bilska AT, Redmer DA \& Reynolds LP 2006 Effects of estradiol- $17 \beta$ on expression of mRNA for seven angiogenic factors and their receptors in the endometrium of ovariectomized (OVX) ewes. Endocrine 30 333-342. (doi:10.1007/s12020-006-0012-5)

Jolly PD, Tisdall DJ, De'ath G, Heath DA, Lun S, Hudson NL \& McNatty KP 1997 Granulosa cell apoptosis, aromatase activity, cyclic adenosine $3^{\prime}, 5^{\prime}$-monophosphate response to gonadotropins, and follicular fluid steroid levels during spontaneous and induced follicular atresia in ewes. Biology of Reproduction 56 830-836. (doi:10.1095/biolreprod56.4.830)

Kidder GM \& Mhawi AA 2002 Gap junctions and ovarian folliculogenesis. Reproduction 123 613-620. (doi:10.1530/rep.0.1230613)

Krysko DV, Diez-Fraile A, Criel G, Svistunov AA, Vandenabeele P \& D'Herde K 2008 Life and death of female gametes during oogenesis and folliculogenesis. Apoptosis 13 1065-1087. (doi:10.1007/s10495-0080238-1)
Leyva V, Buckrell BC \& Walton JS 1998 Regulation of follicular activity and ovulation in ewes by exogenous progestagen. Theriogenology $\mathbf{5 0}$ 395-416. (doi:10.1016/S0093-691X(98)00148-4)

Lingenfelter BM, Dailey RA, Inskeep EK, Vernon MW, Poole DH, Rhinehart JD \& Yao J 2007 Changes of maternal transcripts in oocytes from persistent follicles in cattle. Molecular Reproduction and Development 74 265-272. (doi:10.1002/mrd.20568)

Mattioli M, Barboni B, Turriani M, Galeati G, Zannoni A, Castellani G, Berardinelli P \& Scapolo PA 2001 Follicle activation involves vascular endothelial growth factor production and increased blood vessel extension. Biology of Reproduction 65 1014-1019. (doi:10.1095/ biolreprod65.4.1014)

Mihm M, Curran N, Hyttel P, Knight PG, Boland MP \& Roche JF 1999 Effect of dominant follicle persistence on follicular fluid oestradiol and inhibin and on oocyte maturation in heifers. Journal of Reproduction and Fertility 116 293-304. (doi:10.1530/jrf.0.1160293)

Pant D, Reynolds LP, Luther JS, Borowicz PP, Stenbak TM, Bilski JJ, Weigl RM, Lopes F, Petry K, Johnson ML et al. 2005 Expression of connexin 43 and gap junctional intercellular communication in the cumulus-oocyte complex in sheep. Reproduction 129 191-200. (doi:10. 1530/rep.1.00434)

Rawlings NC, Jeffcoate IA \& Rieger DL 1984 The influence of estradiol-17 and progesterone on peripheral serum concentrations of luteinizing hormone and follicle stimulating hormone in the ovariectomized ewe. Theriogenology 22 473-488. (doi:10.1016/0093-691X(84)90047-5)

Redmer DA \& Reynolds LP 1996 Angiogenesis in the ovary. Reviews of Reproduction 1 182-192. (doi:10.1530/ror.0.0010182)

Redmer DA, Aitken RP, Milne JS, Reynolds LP \& Wallace JM 2005 Influence of maternal nutrition on messenger RNA expression of placental angiogenic factors and their receptors at midgestation in adolescent sheep. Biology of Reproduction 72 1004-1009. (doi:10.1095/biolreprod.104.037234)

Revah I \& Butler WR 1996 Prolonged dominance of follicles and reduced viability of bovine oocytes. Journal of Reproduction and Fertility $\mathbf{1 0 6}$ 39-47. (doi:10.1530/jrf.0.1060039)

Schrick FN, Surface RA, Pritchard JY, Dailey RA, Townsend EC \& Inskeep EK 1993 Ovarian structures during the estrous cycle and early pregnancy in ewes. Biology of Reproduction 49 1133-1140. (doi:10. 1095/biolreprod49.5.1133)

Sirois J \& Fortune JE 1990 Lengthening the bovine estrous cycle with low levels of exogenous progesterone: a model for studying ovarian follicular dominance. Endocrinology 127 916-925. (doi:10.1210/endo127-2-916)

Tsai MY, Lan KC, Huang KE, Huang FJ, Kung FT \& Chang SY 2003 Significance of mRNA levels of connexin 37, connexin 43, and connexin 45 in luteinized granulosa cells of controlled hyperstimulated follicles. Fertility and Sterility 80 1437-1443. (doi:10.1016/j.fertnstert. 2003.05.015)

Vinoles C, Meikle A, Forsberg M \& Rubianes E 1999 The effect of subluteal levels of exogenous progesterone on follicular dynamics and endocrine patterns during early luteal phase of the ewe. Theriogenology $\mathbf{5 1}$ 1351-1361. (doi:10.1016/S0093-691X(99)00079-5)

Weber LP, Kiparissis Y, Hwang GS, Niimi AJ, Janz DM \& Metcalfe CD 2002 Increased cellular apoptosis after chronic aqueous exposure to nonylphenol and quercetin in adult medaka (Oryzias latipes). Comparative Biochemistry and Physiology - Part C: Toxicology \& Pharmacology 131 51-59. (doi:10.1016/S1532-0456(01)00276-9)

Received 31 January 2010

First decision 2 March 2010

Revised manuscript received 28 June 2010

Accepted 15 July 2010 